\title{
Trabalhadoras na cidade: interpretações sobre tempos, trajetórias e percepções “no” século XXI
}

\section{Trabajadoras en la ciudad: interpretaciones sobre tiempos, trayectorias y percepciones “en" el siglo XXI}

\author{
Gabriela Vergara ${ }^{1}$
}

\begin{abstract}
Resumo: Cidades, trabalhos e sensibilidades conformam um complexo cenário para sua indagação que encontram em práticas cotidianas de trabalhadores da cidade, um ponto chave por onde se torna visível a estruturação social. Assim, entre o trabalho por conta própria (trabalhador autônomo), a subocupação setorizada, a informalidade e, a feminização por um lado, junto com novas ontologias e metamorfoses aparecem reconfigurações do mundo do trabalho acompanhadas por novas sensibilidades. Uma das dimensões das metamorfoses do mundo do trabalho é a feminização, a qual veio acompanhada de duas dualidades que se tensionam: os lares com dois provedores e a dupla jornada de trabalho (produtivo e reprodutivo) que, principalmente as mulheres têm sob sua responsabilidade. Neste artigo nos propomos analisar como se instanciam cotidianamente as metamorfoses do mundo do trabalho a partir das experiências de duas muIheres que trabalham em setores tipicamente femininos na cidade: a docência e o comércio. Para isso distinguimos duas dimensões: trajetórias e tempos de trabalhos por um lado, e percepções por outro. Finalmente, daremos conta como as relações entre classe social e gênero reconfiguram e complexificam o cenário atual do mundo do trabalho.
\end{abstract}

Palavras-chave: trabalhadoras urbanas, trajetórias, percepções.

\begin{abstract}
Ciudades, trabajos y sensibilidades conforman un complejo escenario para su indagación que encuentran en prácticas cotidianas de trabajadores de la ciudad, un lugar clave por donde se hace visible la estructuración social. Así, entre el cuentapropismo, la subocupación sectorizada, la informalidad y, la feminización por un lado, junto con nuevas ontologías y metamorfosis aparecen reconfiguraciones del mundo del trabajo acompañadas por nuevas sensibilidades. Una de las dimensiones de las metamorfosis del mundo del trabajo es su feminización, la cual vino acompañada de dos dualidades que se tensionan: los hogares con dos proveedores y la doble jornada de trabajo (productivo y reproductivo) que, principalmente tienen bajo su responsabilidad las mujeres. En este artículo analizamos cómo se instancian cotidianamente las metamorfosis del mundo del trabajo a partir de las experiencias de dos mujeres que trabajan en sectores típicamente femeninos en la ciudad de San Francisco (Córdoba, Argentina): la docencia y el comercio. Para ello distinguimos dos dimensiones: trayectorias y tiempos de trabajos por un lado, y percepciones por otro.
\end{abstract}

\footnotetext{
${ }^{1}$ Investigadora adjunta del CONICET- Universidad Nacional de Villa María (UNVM). Profesora asociada en Universidad Nacional de Rafaela (UNRAF) en las cátedras Universidad Sociedad y Conocimientos y Pensamiento Político y Social. Doctora en Ciencias Sociales. Magister en Ciencias Sociales. Lic. en Sociología. Investigadora del Centro de Investigaciones y Estudios Sociológicos (CIES) y de GESSYCO (Grupo de Estudios sobre Subjetividades y Conflictos).vergara.gabriela@outlook.com
} 
Finalmente, damos cuenta de cómo las relaciones entre clase social y género reconfiguran y complejizan el escenario actual del mundo del trabajo.

Palabras-Clave: Trabajadoras en la ciudad, trayetórias, percepciones.

\section{Introdução}

Os desenvolvimentos vertiginosos da tecnologia e as consequentes conexões e desconexões espaço-temporais, o avanço da globalização econômica da mão de corporações transnacionais, o constante desdobramento de atividades extrativistas de bens comuns no Sul Global, a manutenção de uma divisão internacional do trabalho (que se complexifica em termos de gêneros, etnias e idades), a dualidade na mão de obra entre uma minoria que trabalha em postos altamente qualificados e uma grande parte dos empregados que transitam na subocupação, a feminização da mão de obra e das migrações por trabalho, são alguns dos principais processos identificados em escala mundial nos últimos 30 anos.

Estas transformações supõem especificidades em função de contextos particulares, como no caso de cidades intermediárias (no que se refere à população), como San Francisco ${ }^{2}$, que apresentam duas particularidades. Por um lado, centros urbanos que assistiram em meados do século $\mathrm{XX}$ a um forte processo de industrialização - no marco da Industrialização por Substituição de Importações (ISI)- e, por outro, que se situam geograficamente em uma região com um forte perfil agroexportador, especialmente de grãos.

Por outro lado, temos interpretado diferentes avaliações com respeito à desindustrialização na cidade na relação passado-presente-futuro (VERGARA, 2006), mais adiante analisamos como a vergonha opera de maneira tensional diante dos olhares dos outros que desvela o estigma da expulsão e o orgulho pelo trabalho que se tem, tensão entre o que poderíamos denominar "queria algo melhor" versus "não resta outra opção" (VERGARA, 2009). Também indagamos os lugares do medo que estão presentes nas experiências daqueles que trabalham nas ruas, como catadoras de lixo, como uma pri-

\footnotetext{
${ }^{2}$ A cidade está situada no limite leste da cidade de Córdoba (Argentina). Segundo o Censo Nacional de População, Vivienda y Hogares de 2010, San Francisco, tinha 62.211 habitantes. Por sua vez, Frontera (com uma população de 10.723 habitantes) e o Barrio Acapulco y Veracruz da localidade de Josefina (com 2.142 pessoas), constituem centros urbanos contíguos a San Francisco, mas pertencentes à Santa Fe. Estimamos que em 2010, o aglomerado alcançou uma população de aproximadamente 75.000 habitantes.
} 
meira maneira de mostrar outras vivências com respeito ao emotivo em seu cruzamento com a classe (grupo social). Assim, o medo ao de-outra-classe não se faz presente nos "corpos precarizados" dado seu caráter de expulsão e desfiliação, senão que se conecta com outras esferas da vida cotidiana. (VERGARA, 2013). Na relação entre sensibilidades e segregação sócio-espacial interpretamos como se dão as práticas de (i)mobilidade em outra cidade cordobesa (VERGARA; FRAIRE, 2017).

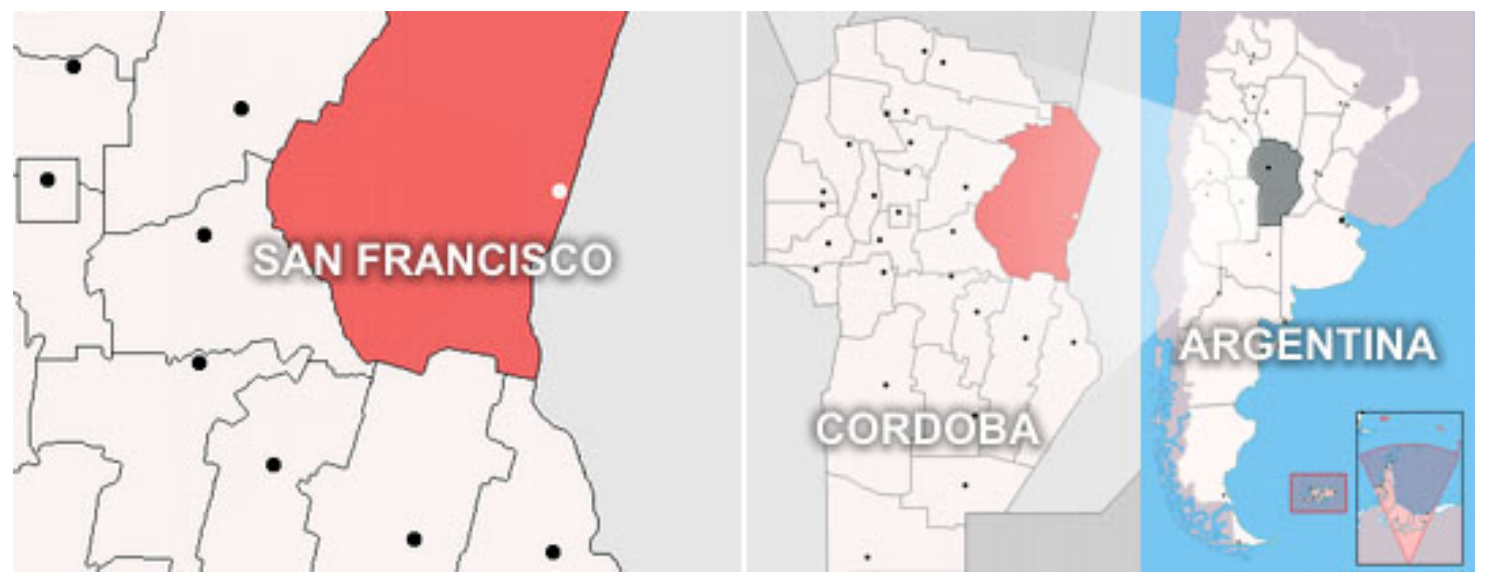

Figura 1. Mapas de localização de San Francisco em Córdoba (Argentina). Fonte: Disponível em: http://www.solsoft.com.ar/vari/img/map.jpg

Cidades, trabalhos e sensibilidades conformam um complexo cenário para sua indagação que encontram em práticas cotidianas de trabalhadores da cidade, um lugar chave por onde se torna visível a estruturação social. Assim, entre o por conta própria (trabalhador autônomo), a subocupação setorizada, a informalidade e, a feminização por um lado, junto com novas ontologias e metamorfoses aparecem reconfigurações do mundo do trabalho acompanhadas por novas sensibilidades que naturalizam - sem ocultar - as marcas de uma contínua expropriação de energias corporais em relação a diferentes modalidades (VERGARA, 2018a). Neste contexto, temos identificado relações entre geometrias corporais, sensibilidades e gramáticas da ação que configuram sensibilidades baseadas no individualismo solidário por um lado, e um individualismo da impotência e da resignação por outro (VERGARA, 2018b) No caso dos trabalhadores, temos advertido traços do que denominamos sensibilidades dos sobreviventes e dos 'surfientes'3 (VERGARA, 2017).

\footnotetext{
${ }^{3}$ É uma derivação do termo surfistas, pessoas que praticam o surf. É uma expressão metafórica utilizada para denominar àqueles que acreditam que podem enfrentar obstáculos e atingir seus objetivos sem problemas, orgulhosos do que fazem e de suas conquistas. São opostos aos sobreviventes, que têm uma
} 
Ainda, uma das dimensões das metamorfoses do mundo do trabalho é a feminização, a qual veio acompanhada de duas dualidades que se tensionam: os lares com dois provedores e a dupla jornada de trabalho (produtivo e reprodutivo) que, principalmente as mulheres têm sob sua responsabilidade. Com respeito a isso, por outro lado, temos analisado como as mulheres 'recuperadoras de resíduos' (catadoras de lixo) provêm por serem donas de casa (VERGARA, 2015) e, poderíamos acrescentar, de modo inverso por ser donas de casa - conhecem as necessidades, os costumes, as rotinas, provêm.

Neste artigo que se inscreve no marco de dois projetos de pesquisa ${ }^{4}$ nos propomos analisar como se instanciam cotidianamente as metamorfoses do mundo do trabaIho a partir das experiências de duas mulheres que trabalham em setores tipicamente femininos na cidade: a docência e o comércio. Para isso distinguimos duas dimensões: trajetórias e tempos de trabalhos por um lado, e percepções por outro.

A estratégia argumentativa proposta é a seguinte: em primeiro lugar apresentamos as noções principais que, desde uma sociologia dos corpos e das emoções nos permitem entender o trabalho. Desde esta perspectiva nos centramos no tempo e trajetórias como parte da posição e condição de classe por um lado, e das percepções como componentes das sensibilidades que nos permitem compreender mecanismos de naturalização e suportabilidade.

Em um segundo momento, analisamos entrevistas realizadas em San Francisco em 2017, com mulheres que se encontram/encontravam em atividade docente e no comércio varejista.

Nas Considerações Finais refletimos sobre as formas como se distribuem as energias corporais no século XXI em mulheres com dupla jornada e em lares de dois provedores. Mais além das leituras com foco feminista que poderiam ser feitas, daremos conta como as relações entre classe social e gênero reconfiguram e complexificam no cenário atual do mundo do trabalho.

sensibilidade melancólica do que perderam no passado e já não têm mais (Vergara, 2017).

${ }^{4}$ Plano de trabalho CONICET 2016-2017 "Sensibilidades em tensão: Trabalhos, ações coletivas e muIheres. Uma análise desde a estruturação social em San Francisco e Villa María (2002-2016)" e "Transformações no mundo do trabalho: estrutura produtiva, organização do trabalho e formas de ocupação (San Francisco, 2001-2017)", aprovado pelo Instituto de Pesquisas da Universidade Nacional de Villa María, bianual (2016-2017), Dir, Gabriela Vergara. 


\section{Os corpos mais além das dicotomias}

Neste tópico nos propomos explicitar desde uma sociologia dos corpos e das emoções as principais hipóteses para entender o trabalho. A partir disto, desenvolvemos a dimensão do tempo como parte da existência em termos gerais, e a forma que adquire como trajetória no trabalho (assalariado). Ditas trajetórias no curso das biografias dos agentes sociais formam parte das posições e condições de classe. Isto delineia certas práticas e percepções no marco dos processos de estruturação social do capitalismo do século XXI.

\subsection{Trabalhos, energia e mundo}

Desde uma sociologia dos corpos e das emoções (SCRIBANO, 2012) assumimos que os agentes participam no mundo e nas relações sociais a partir de seus corpos. Uma maneira possível de explicar, isto é, a partir da noção de tramas corporais (VERGARA, 2012a), as quais se configuram a partir de três dimensões entrelaçadas. Uma, é de caráter orgânico/biológico - os processos e funções vitais, desde o nascimento, 0 crescimento, a reprodução e a morte-; outra subjetiva (ou o "eu corporizado" que inclui as percepções do agente sobre si mesmo) e, a incorporação do social (hábitos, práticas, gestos, linguagens). Estas dimensões se combinam com dois vetores básicos da existência. O corpo no tempo, configura uma biografia como condensação e síntese das vivências e experiências que articulam a sua vez, o particular e individual de cada agente com os processos sócio-históricos nos que há vivido. O corpo no espaço, implica as posições, condições e disposições de ação, desde onde também se constitui a forma de conhecer e sentir o mundo.

As tramas corporais e as emoções se conectam com os processos de estruturação social e vice-versa, dado que os corpos no capitalismo são um dos pontos chave para a sua reprodução e metamorfose constante a partir da expropriação de energias. Mas, além disso, porque se identificam dispositivos e mecanismos que, interferindo nas práticas e percepções, evitam, ocultam ou coagulam os conflitos, garantindo certa estabilidade a nível global. No caso dos países dependentes e neocoloniais como os latinoamericanos, atravessados pela depredação dos bens comuns e as metamorfoses no mundo do trabalho, o capitalismo adquire particulares características sob a mesma lógica 
que Marx descreveu no século XIX. Por isso interessa retomar algumas precisões desde esta perspectiva.

Marx define ao homem desde sua corporeidade, vitalidade, sensorialidade, com as que se relaciona com o mundo e com seus semelhantes. Isto "significa que tem objetos reais, sensoriais como objeto de seu ser, de sua expressão vital ou que só pode expressar sua vida em objetos reais, sensoriais" (MARX, 2004, p.198). A corporeidade é tanto da natureza como social e se inscreve num conjunto de relações que o indivíduo mantém com seu entorno através e a partir de cada um dos sentidos, como suas atividades de pensar, intuir, sentir, desejar, atuar, amar, os quais conformam modos diversos de apropriação. Quer dizer, o homem através de cada uma das suas faculdades sensoriais e corporais se apropria do mundo, para realizar-se enquanto tal. Faculdades e sentidos tanto físicos, como práticos (vontade, amor) junto com uma sensibilidade que o afirmam no prazer (MARX, 2004), conformam uma unidade complexa, plena, que é o ser humano.

Desde o realmente perceptível que é "a organização corpórea destes indivíduos e, como consequência disto, seu comportamento em relação ao resto da natureza" (MARX; ENGELS, 1970, p. 19), se deriva que a diferença com os animais radica em que os indivíduos são capazes de criar e construir objetos para satisfazer suas necessidades. Em contato com seu meio, com o mundo sensorialmente acessível, os homens produzem as sociedades e inversamente, e devido a esta íntima relação, sua atividade e capacidade de prazer se voltam eminentemente sociais, daí que a sociedade seja "a unidade essencial plena do homem com a natureza" (MARX, 2004, p.144). E nesta relação com a natureza há "um gasto de força de trabalho humano" (MARX, 1975, p. 54), dado que consome energias corporais e põem em uso suas capacidades. Portanto, o trabalho é um processo mediante o qual, o homem controla, regula sua relação com a natureza, como um "cúmulo" energético vinculado ao processo de produção que garante os meios para subsistir: ambas dimensões põem em "jogo" uma corporeidade nunca estática senão que igualmente construída bio-socialmente. (VERGARA; LISDERO, 2017).

Diferente dos animais, o homem tem que fazer sua existência e, diante das situações deve concretizar uma apropriação mediante uma "mediação", a qual se dá sob a forma dos processos de produção e reprodução, irredutíveis ao econômico. Por isso, “(...) 
neste fazer consciente, que é mediação, nesta contínua produção e re-produção da existência humana está o fundamento (diante do imediato deixar-acontecer vg da existência animal) do trabalho" (MARCUSE, 1970, p. 24).

A lógica da produção e reprodução humana transcende os gêneros com o qual sem assumir uma noção feminista do trabalho ${ }^{5}$, podemos compartilhar a ideia de que a (re)produção da vida deveria ser a meta principal do trabalho, ao qual podemos agregar, donde o próprio trabalho não seja um valor de troca, quer dizer, uma mercadoria.

\subsection{Tempos de trabalhos e trajetórias de classe}

Neste segundo momento, desenvolvemos a dimensão do tempo e a configuração das trajetórias como uma dimensão possível para analisar as metamorfoses no mundo do trabalho desde a última década do século XX até a atualidade.

Como expomos acima, as dimensões do espaço e do tempo atravessam as tramas corporais. No contexto deste artigo, nos centraremos nos tempos dos trabalhos como formas de expropriação e nos tempos dos corpos no trabalho como trajetórias. Tempos e corpos dão conta de uma lógica de expropriação das energias sociais e naturais, e de regulação das emoções para garantir um grau mínimo no qual o sistema se torne suportável. As fantasias e os fantasmas sociais - senso Scribano- tendem precisamente a desancorar as práticas de seus tempos e momentos, borrando as mediações, invertendo um particular que ocupa o lugar de um universal, repetindo as derrotas nos conflitos. A vida cotidiana então, se traduz em um "sempre foi assim", em um "seguir sendo/seguir estando". Em outro lugar (VERGARA, 2012b), temos analisado a lógica do tempo em relação ao gasto festivo, como prática intersticial.

Ainda, em termos sociológicos, o tempo tem sido objeto de indagação no marco do processo da civilização (ELIAS, 1989), podendo distinguir-se em termos gerais, em relação às práticas dos agentes e das instituições, em sua reversibilidade ou em sua irreversibilidade (GIDDENS, 1995). Também tem sido um eixo chave na análise de esquemas de percepção em trabalhadores, no contexto de passagem de uma economia

\footnotetext{
5"Um conceito feminist do trabalho tem que estar orientado para a reprodução da vida como meta do trabalho e não a produção de objetos e de riqueza, na qual a produção da vida é uma derivação secundária" (Mies, 1994, p.217).
} 
tradicional/rural para uma moderna/urbana, com seus consequentes efeitos sobre como é percebido o futuro em termos políticos (BOURDIEU, 2006).

Para o capitalismo, o tempo tem sido uma das chaves para sua expansão. $\mathrm{Na}$ análise que Max Weber (2003) propõe sobre sua origem, o tempo é uma das dimensões na existência dos calvinistas que opera como regulador das práticas. O tempo deve ser utilizado sem desperdícios, sem ócio, para encontrar provas de salvação.

Marx interpretou o tempo em relação aos corpos e suas energias no transcurso da jornada laboral, para identificar ali a lógica da mais-valia que se trama nas pregas da quantidade de horas e de pagamento. Por isso, a mais-valia se dá com maior intensidade nas economias onde o valor de troca é mais importante que o valor de uso, porque exige que a circulação das mercadorias seja mais rápida. A jornada de trabalho se compõe do tempo de trabalho realmente necessário (para sua produção como qualquer outra mercadoria, neste caso da mercadoria força de trabalho humana) e o tempo extra de trabalho, que no capitalismo sempre está presente. Ainda que não existam limites mínimos para esta jornada de trabalho, os limites máximos se encontram nos aspectos morais - de acordo com a época- e físicos.

Do ponto de vista do trabalhador, Marx esclarece: "o consumo da mercadoria não pertence ao vendedor que a vende, mas ao comprador que a adquire. Te pertence, portanto, o uso da minha força de trabalho diária. Mas por intermédio de seu preço diário de venda eu devo reproduzi-la diariamente e, portanto,poder vendê-la de novo. Deixando de lado o desgaste natural pela idade, etc., amanhã estarei em condições de trabalhar com o mesmo estado normal de vigor, saúde e altivez que hoje. Constantemente me proclamas o evangelho da "poupança/preguiça" e da "abstinência/corpo mole". Concordo! Quero economizar a força de trabalho, como um administrador racional e econômico de meu único patrimônio, e abster-me de todo desgaste insensato da mesma." (Marx, 1975, p. 280).

A relação entre trabalho como mercadoria que se vende, tempo para reprodução e a economia/desgaste de energias nos interpela ainda no século XXI, quando as práticas dos empregadores continuam operando sob a lógica de "gastar ao trabalhador até despedi-lo". 
Por isso, a mais-valia segue mostrando a falácia do intercâmbio de equivalentes pelo dinheiro, porque em realidade existe uma apropriação diferencial, entre uma parte e outra da relação. Mas, se esta é a lógica principal do tempo, do capitalismo e dos corpos, a outra tem que ver com um trabalho que fique resumido no valor da reprodução da força de trabalho, quer dizer, o trabalho de reprodução que historicamente ficou a cargo das mulheres e/ou outros integrantes do núcleo familiar. No contexto de uma divisão internacional do trabalho, onde o sistema de escravidão pode ser posto em relação com o sistema de trabalho assalariado europeu desde o século XVI, se adverte que:

\begin{abstract}
"a história do chá, do açúcar, do rum, do tabaco e do algodão é muito importante para o surgimento do sistema fabril (...) o que viajava com estas «exportações» não era somente o sangue dos escravos senão o germe de uma nova ciência da exploração [humana] e de uma nova divisão da classe trabalhadora, pela qual o trabalho assalariado, mais que prover uma alternativa à escravidão, foi convertido em dependente da escravidão como um mecanismo para ampliar a parte não paga do dia de trabalho assalariado (da mesma forma que o trabalho feminino não pago)". (FEDERICI, 2010, p. 160).
\end{abstract}

As conexões entre o sistema de escravidão e a construção social da mulher como dona de casa revelam como o capitalismo encontra mecanismos para obter maiores ganhos a partir do ganho principal, a mais-valia.

Daí que, visibilizar o trabalho doméstico em busca da equidade não é suficiente já que devem ser postos em relação ambos tipos de trabalho, por exemplo na possibilidade de reproduzir a força de trabalho como na contenção afetiva que absorve conflitos. Em outras palavras: "[o] processo de acumulação utiliza as energias humanas como mercadorias e a tarefa do trabalho doméstico é reproduzir essas energias como parte integrante das pessoas, tarefa que, no entanto, deve desenvolver-se dentro dos limites de sua reprodução como mercadoria" (PICCHIO, 1994, p. 455).

Se os tempos nos trabalhos são uma das dimensões que conectam corpos, trabaIhos, a outra dimensão tem que ver com inscrever esses corpos em posições e condições de classe, no marco de uma estrutura social que se (re)constrói constantemente. Por isso nos interessa repassar algumas considerações que nos permitam inscrever as trajetórias como trabalhadoras assalariadas, as quais formam parte das trajetórias de classe que se configuram no tempo biográfico e social entre posições e condições de classe.

As classes sociais ocupam uma posição e se localizam em um plexo de relações 
que as conectam com as outras partes componentes da estrutura social. As posições têm propriedades de posição e propriedades de situação/localização. Dentro das primeiras, pode-se diferenciar entre as sincrônicas e do devir com o qual "o ponto da trajetória captado por um corte sincrônico, encerra sempre o declive do trajeto social: portanto, sob pena de deixar escapar de um ascenso ou de um descenso, como promoção ou retrocesso, é necessário caracterizar cada ponto pela diferencial da função que expressa a curva, quer dizer, por toda a curva" (BOURDIEU, 2002, p. 125).

Por isso, a estrutura como totalidade e o tempo transcorrido da posição formam seu contexto que habilita a fazer uma análise comparativa e interpretativa dos casos. Estas noções conceituais nos permitirão incomodar as experiências das trabalhadoras.

\subsection{Percepções: algo mais que um ponto de vista}

Uma maneira possível de compreender as experiências das trabalhadoras no capitalismo atual é ver as configurações que se dão entre as tramas corporais e sensibilidades, uma vez que as políticas das emoções se tornaram um eixo crucial da dominação. Segundo Scribano, "[as] condições materiais de existência são justamente as vivências de um sistema que tecendo uma sociabilidade aceitável/aceita, elabora sensibilidades que naturalizam a renúncia" (SCRIBANO, 2013b, p. 39), sendo resultado de uma relação dialética entre percepções, emoções e sensações (SCRIBANO, 2007a). Deste modo, as sensibilidades se configuram a partir de sua inscrição nos processos de estruturação social que tramam as relações sociais e as práticas cotidianas.

Neste contexto, as percepções interessam porque dado seu vínculo com a condição corporal de todo agente, nos permitem observar as formas naturalizadas de ver e organizar o mundo. A partir da relação corpo-mundo, as percepções se conectam com as impressões e as sensações, que se organizam de acordo com padrões socioestruturais de interpretação e tipificação gerados segundo os lugares sociais que ocupam os corpos. Por isso a posição ocupada configura um ponto de vista particular a partir do qual se vê o mundo. Mas desde uma postura realista e crítica assumimos em termos ontológicos que o mundo tem estruturas variáveis com mecanismos de funcionamento próprios pelo qual a sociedade tem uma existência própria de maneira independente daqueles que a conhecem. Num sentido epistemológico, o conhecimento científico depende e está 
condicionado pela sociedade (SCRIBANO, 2008).

Daí que se toda percepção é a combinação de alguém que percebe um objeto num contexto determinado, devemos considerar a construção social dos agentes e, dos contextos, o qual envolve hierarquias sociais dos sentidos, tecnologias da comunicação, a informação e o entretenimento, processos de estruturação e enclaves, entre outros.

A ideia durkheimiana dos princípios de classificação que dispunham as sociedades simples para distinguir o sagrado do profano, como base para a religião reaparece como um dos componentes do habitus, na obra de Pierre Bourdieu.

A percepção é gerada de acordo com os lugares sociais que ocupam os corpos; lugares diferentes e diferenciais, sobretudo, numa sociedade capitalista. Precisamente pelo estreito vínculo que tem o perceptor enquanto sujeito encarnado numa posição, é que a corporeidade e o mundo conduzem a não poder associar a percepção com a imagem ou o ato cognitivo de um indivíduo isolado, externo e puramente racional. Desaparece a ideia de um observador diante do mundo como uma coisa posta diante dele, como um "espetáculo ou representação suscetível de ser apreendida de relance" (BOURDIEU, 1999, p. 188). Esta é uma característica que permite deixar de lado aquelas considerações com respeito ao externo e ao interno, da percepção como uma cópia diferente do real ou bem como uma mediação entre o objeto e a representação; do realismo e do fenomenalismo. Perceber não é só captar as impressões dos sentidos, ainda que isso seja uma parte importante do processo; envolve além do mais componentes socialmente estruturados que reafirmam a conexão corpo-mundo.

Para Bourdieu (1990), as percepções do mundo social têm componentes objetivos e subjetivos. Ocupar um lugar no mundo é ter uma posição que geometricamente sempre implica uma racionalidade com outros, capacidades diferenciais de apropriação e diferentes propriedades. Nas sociedades capitalistas, os lugares são diferenciáveis e diferentes em relação à capacidade de apropriação - expropriação de recursos, energias, bens, serviços. Este lugar ocupado na estrutura social é um dos componentes que fazem o agente-perceptor. O componente subjetivo está formado por esquemas de percepção e apreciação que denotam uma temporalidade ancorada nas disputas que se dão em determinado campo, tal como acontece na percepção artística. Assim Poe exemplo, 
gostar e disfrutar das pinturas no século XV foi o resultado de práticas cotidianas, cujos esquemas podem ser identificados - de maneira analítica - dentro de uma estrutura de associação/oposição (BOURDIEU, 2003).

Os esquemas organizam o espaço, o tempo, as relações sociais, se tornam práticas e se fazem com elas, envolvem o mundo conhecido pelo corpo, por suas posturas, por suas maneiras de estar que permitem distinguir e diferenciar objetos, agrupá-los, contrastá-los com outros. Estes esquemas de classificação se complementam e articulam com formas de apreciar, de avaliar, do gosto com relação a tais objetos. Estes esquemas que classificam, que diferenciam se configuram desde o corporal, em função do lugar que ocupa na estrutura social mas também a partir dos percursos biográficos que - ainda que nunca se desprendam de seus condicionamentos objetivos- podem apresentar particularidades. Desta forma, a percepção se configura socialmente ao longo da biografia, ao longo do processo de constituição da corporeidade, ao longo da construção intersubjetiva da subjetividade. Por outro lado (VERGARA, 2015) temos identificado esquemas os sagrado/profano, sagrado para o lar e provisão por privação como os componentes principais da (auto)percepção das mulheres provedoras enquanto donas de casa (tensionando assim, o clássico modelo do varão provedor). No seguinte bloco analisamos/utilizamos esta perspectiva conceitual para a análise das entrevistas.

\section{Mulheres, mães e assalariadas}

Neste tópico nos propomos a analisar profundamente duas entrevistas realizadas em San Francisco em 2017, com uma ex-empregada de um comércio de vestuário (G: 50 anos) e uma docente com cargo hierárquico na atualidade (L: 42 anos). Para isso, realizamos uma análise/interpretação por eixos de trajetórias de classe como uma maneira de compreender os aspectos objetivos de suas percepções (1); descrevemos os tempos e práticas dos trabalhos atuais (2) e finalmente, questionamos as percepções sobre seus trabalhos e trajetórias (3). 


\subsection{Energias corporais nas trajetórias e simultaneidades}

L: Eu me formei em 1995 como Professora de Música e Professora de Educação Infantil.(... $)^{6}$ tive a sorte de inserir-me em seguida na docência. (...) comecei a trabalhar como professora de música substituta num jardim de infância... [e] Tinha um Maternal porque esse ano [o governo municipal fechou] as creches [municipais], então havia muitíssimas professoras de educação infantil que tinham ficado sem trabalho (...) E o jardim particular eu tinha com minha irmã que me ajudava e outras professoras (...) depois de um ano e meio, deixo [o cargo na outra cidade] em 99 (...) e decido fechar esse maternal [particular], seguir com o Jardim [do governo] e seguir estudando, começo a Licenciatura em Ciências da Educação em Córdoba e viajo duas vezes por semana... (...) tinha o título de licenciada... na época. Eu tinha começado na "Escola Normal"7 pela noite, como professora de prática... (...) e animei festas de aniversário [de crianças] desde os 16 anos... até que fiquei grávida [de minha filha] aos 29 (...) começamos com outra companheira. (...) sempre íamos a casas de família. Depois nos chamavam para o Dia da Criança nos sindicatos, em lugares assim, em clubes... foi a primeira oportunidade de trabalho e nos saíamos bem, nos saíamos bem. Às vezes tínhamos duas, três [festas]... saíamos de uma e íamos prá outra (...). Quando era professora, também trabalhei em "Colônias de Férias".

Esse percurso não é linear nem sequencial. Formada com dois títulos que a habilitavam para a docência no fim do ensino médio e experiência em trabalhar com crianças animando festas infantis realiza simultaneamente trabalhos em âmbito público e privado. A "sorte" e sua capacidade de "decidir" abrir, fechar ou deixar se dá desde uma base de certezas e seguranças. Por isso gera seus próprios espaços de trabalho no setor privado, enquanto tem possibilidades de seguir estudando para poder ascender e chegar a um cargo hierárquico numa escola para professores que lhe gera estabilidade, responsabilidade e prestígio. Neste relato se observam alguns processos do mundo do trabalho, de maneira indireta, que interessam ressaltar: -como parte do crescimento dos serviços vinculados ao cuidado e como contrapartida da feminização do trabalho (muitas vezes entre o informal e o precário) encontramos três referências: a) a mercantilização do festivo em

\footnotetext{
${ }^{6}$ Os fragmentos transcritos em parágrafos agrupam diferentes recortes da entrevista. Os parênteses com reticências significa que omitimos partes do relato.

${ }^{7}$ Magistério.
} 
seu início, que deriva da expansão de salões de festas infantis, b) o trabalho em clubes como colônias de férias ou outras atividades para crianças, c) os maternais para crianças pequenas antes do ingresso à nível escolar inicial. Esta trajetória que se bifurca, se interrompe e torna a gerar outras oportunidades - ainda que dentro de um mesmo setor de educação no qual trabalha e se forma-, que dá conta da heterogeneidade de formas de trabalho que se abrem/fecham em meados dos 90 e 2000 na cidade.

A seguir apresentamos a outra trajetória:

G: "[sou] dona de casa desde que nasceu meu filho mais velho. (...) Quando estava no [colégio de] ensino médio, ia pela manhã... e pela tarde era secretária de uma médica, pagava dois mangos ${ }^{8}$ mas não importa, eu gostava (...) fiquei um ano e a doutora foi embora [morar em outra cidade] e, trabalhei 15 anos numa loja, a maior de todas, a única que vendia de tudo, não existe mais nenhuma assim na cidade, [vendia] lençóis, mantas, meias, roupas de crianças, roupas de bebê. (Entrevistadora: E estudasses depois do médio?) ... não lhe pedia porque sabia que não podia, então, bom, tentei, tentei, porque eu trabalhava oito horas... o cansaço me matou, tentei... comecei [licenciatura em] Psicologia em [a Universidade de] Córdoba, mas não, não, não, eu acho que fiz uns cinco meses. Chegava em minha casa e nenhum neurônio funcionava para analisar um texto porque estava cansadíssima, era caminhar muito o dia todo, oito horas em pé. Fazia 3 ou 4 anos que eu entrei, fiquei encarregada da seção. (...) [depois encarregada do transporte] ... cheguei até a fazer o balanço da loja (...) o que tu ganhavas pediam prá não dizer, nem todos ganhavam o mesmo, eu cheguei a ganhar um salário oficialmente e um salário e pouco na realidade (...) além disso eu tinha que ficar atenta às vendas, eu estava na venda, o principal era a venda, tudo o mais que davam era extra, eu ficava louca, perdia os cabelos... (...) trabalhávamos ao máximo, íamos meia hora antes ou meia hora depois, mas essas oito horas pior porque se me deixassem fazer horas extras não seriam tão intensas essas oito horas (...) eu acho que deixei de trabalhar para a firma porque eles fecharam em 2000, eu cobrei a indenização [do trabalho registrado, do extra não] mas me deram algo... (...) [e]em 2001 estava trabalhando em [outra loja de roupas] tenho um aborto, então o médico me disse 'a próxima gravidez não vai trabalhar', então fiquei grávida do mais velho, me virei na vida, todos me diziam que eu podia ter tido

\footnotetext{
${ }^{8}$ Expressão coloquial que significa que Ihe pagavam pouco dinheiro.
} 
muitas opções eu podia ter tirado uma licença sem salário por um ano ou pedir que me assegurassem o trabalho de volta, mas eu já sabia que não ia voltar, assim que esperei passar o terceiro mês e mandei o telegrama de renúncia... era a hora: ou construía a minha família ou não a construía nunca mais por causa do relógio biológico".

Nesta trajetória que começa com um emprego de meia jornada informal, continua por quinze anos em uma loja cujo salário também tem uma parte não registrada, segue um ano mais em outra para retirar-se e ser "dona de casa", dá conta de outro tipo de disposições corporais e horizontes de possibilidades, onde entra em tensão o cansaço por estar oito horas de pé e as dificuldades para poder cursar uma carreira universitária. Em seu trabalho na loja adquire reconhecimentos e responsabilidades cada vez maiores no marco de uma polivalência subregistrada numa jornada laboral "intensa". Diferentemente do relato anterior, a heteronímia nos lugares de trabalho é mais acentuada. Isto entra em relação com as possibilidades e impossibilidades de gerar, abrir, buscar oportunidades e, inclusive com a disposição à mobilidade espacial e social. A restrição à maternidade durante 15 anos para não perder o posto no trabalho no que de maneira tácita - e às vezes explícita - operava a norma de "gravidez=demissão" faz com que uma vez conseguida a casa própria, possa se retirar do mercado de trabalho para ser uma "dona de casa" que trabalha eventualmente no comércio de seu marido.

Um olhar sobre as duas biografias nos permite observar como se tecem as posições e condições de classe para configurar os horizontes do possível, como assim também os cenários e as modalidades nas quais as energias podem ser consumidas e expropriadas. Mais prá cá da feminização do trabalho como um processo no qual ambas as mulheres se inscrevem, podemos observar diferenças que resultam em modalidades de expropriação de energias no marco da informalidade e da precarização, das quais uma delas tem sorte para encontrar estabilidade em um cargo docente estatal.

No bloco seguinte descrevemos as práticas atuais de trabalhos produtivos e reprodutivos.

\subsection{Tempos e práticas de trabalhos}

As entrevistadas integram/integraram lares de dois provedores para as quais se supõem particulares modalidades de distribuição de energias corporais para a resolução 
das demandas e necessidades das tarefas implicadas no trabalho remunerado como também no cuidado e atenção de filhos, assim como a limpeza do lar, entre outros.

L: Nós dois somos professores e estamos ganhando mais ou menos o mesmo, e contribuímos os dois da mesma maneira. [minha] contribuição aumentou, estou trabaIhando num só lugar e estou desde a tarde até a noite. E ele, bom... trabalha em três níveis distintos para poder chegar, visses... ao mesmo (...) [fazer um mestrado ou outra especialização] é muito exigente. São atividades todas as semanas, e leituras e... não é fácil (...) sugerimos aos tutores que possam... nos dar mais tempo para poder ler e fazer as coisas com consciência, com responsabilidade e com compromisso. E também muitos que dizem 'Eu não vou perder o meu final de semana para ficar estudando'. Outros expõem a sua argumentação: 'trabalhamos todo o dia na escola, mas depois em casa tens que planejar, tens que fazer um montão de coisas extras... as reuniões, as aulas, os painéis... e quanto te sobra...?' (...) eu não gosto das tarefas da casa. Mas afinal, trato de dar um jeito e de fazê-las com carinho porque também gosto de ter a casa arrumada e limpa. (...) agora tenho uma pessoa que faz isso uma vez por semana, em casa, que me ajuda, que é a irmã de meu marido. Ela não tinha trabalho, não tinha um trabalho fixo... Era secretária de uma clínica e ficou sem trabalho, e agora começou a trabalhar assim... Umas horinhas como empregada doméstica... nos outros dias eu varro, acomodo, cozinho, ponho a mesa, lavo os pratos, estendo a roupa, passo o indispensável... E tiro um pouquinho do pó a cada dois dias, ou varro, não todos os dias mas trato de manter em ordem, porque é como que essa ordem me dá uma paz. (Entrevistadora: E o resto dos integrantes da família colaboram?) Sim, sim... [marido] colabora bastante, por aí, de noite é ele quem se encarrega da comida... algumas vezes lava os pratos... Algumas vezes também, por aí, está sobrecarregado com as meninas que à noite sempre eu estava e agora eu não estou. Então, é ele quem dá banho nelas... tomam banho sozinhas mas ele está por aí, supervisionando... Cuida da roupa delas, põe a roupa prá lavar, Ihes dá comida. A mais velha o ajuda bastante. (...) E a menorzinha não... Ou seja, ela é a mimada da casa... Ela tem seu tempo, seu ritmo. [marido]me ajuda muito e [filha] também, dentro do que pode".

Neste fragmento da entrevista de L. identificamos três aspectos que dão conta de práticas e tempos da vida cotidiana. A distribuição de horários diversos que permite o 
trabalho docente redunda em uma complementaridade entre ambos provedores do lar, entre os que se destaca que o salário da entrevistada é maior e unificado em uma mesma instituição e horários concentrados. A partir destes trabalhos remunerados se deriva a necessidade de realizar outras capacitações e formações que demandam outros tempos e exigências. Por isso a solicitação de prorrogações e extensões em um contexto no qual o cansaço se manifesta em um duplo sentido a partir de comentários de colegas: descansar o fim de semana, ou melhor, de todas as atividades associadas a um cargo docente. Tempos que demandam energias que não se têm para seguir estudando. O terceiro aspecto tem a ver com a distribuição de responsabilidades e execução das diferentes tarefas que abarca o trabalho reprodutivo. Em relação a isso se observa como L. segue ocupando um lugar central (como responsável e executora de atividades concretas que enumera com clareza) em que pese ser um lar com dois provedores similares. Ajudas e colaborações brindadas pelo marido e pela filha mais velha não conseguem reduzir as frequências com que tem que varrer, cozinhar, lavar.

Vejamos a distribuição de tempos e práticas relacionadas a outra entrevistada:

G: "surgiu para meu marido quando ainda não tínhamos filhos, a possibilidade de comprar um negócio que é o negócio que ele tem faz 20 anos que é um mercadinho então eu the disse: 'arriscamos o salário menor - que era o dele - te arrisca agora que não temos filhos ou não nos arriscamos nunca mais'... (...) três horas por dia vou ajudá-lo [no negócio do marido] para que não fique sozinho ou seja sigo em contato com gente, sigo atendendo ou vendendo, mas como é outra loja de venda de produtos diversos o mercadinho (...) quando me surgiu vai fazer três anos atrás uma proposta de trabalho importantíssima, muito boa, mas como eu não tinha família aqui, isso mudava tudo, nas atividades de meus filhos".

Os tempos de uma mulher dona de casa se redistribuem quase invisivelmente entre a atividade laboral autônoma do marido e tudo o que implica o lar e a criação dos filhos. Tempos e custos que são avaliados na hora de conseguir outro trabalho, dado que sem familiares (pais ou mães, irmãs ou irmãos) disponíveis, o trabalho reprodutivo transforma-se em serviços terceirizados pagos: ônibus ou transporte escolar, babás ou empregada doméstica, entre outros. 
As biografias e práticas atuais dão conta de um complexo cenário de energias corporais e sociais que se distribuem com diferentes intensidades e modalidades. No caso da docente, a simultaneidade de trabalhos de outrora se substitui por um só posto hierárquico que inscreve tempos extras além das contínuas formações, ao que se acrescenta o trabalho cotidiano em um lar que, ainda que pese a existência de dois provedores as responsabilidades do reprodutivo ficam claramente a cargo da mulher.

No lar de uma "dona de casa" que durante 15 anos trabalhou intensamente em uma loja ganhando quase um salário extra se concentram as energias para o cuidado dos filhos, para o trabalho reprodutivo. O tempo biológico, segundo a entrevistada, the marcou um limite para a maternidade uma vez que tinham casa própria, o qual se inscreve em uma biografia com maior heteronomia que a docente (a médica que vai embora morar em outra cidade, a loja fecha, não pode estudar, etc.).

\subsection{Percepções}

Neste capítulo analisamos duas dimensões que nos permitem montar como um quebra-cabeças no qual colocamos as percepções no contexto de práticas e bibliografias. Uma delas diz respeito às (auto) percepções de classe (1) e, a outra corresponde as (auto)percepções de si em relação ao trabalho. Começamos com as percepções de classe da docente:

L: "me considero uma classe média porque nos damos alguns luxos, mas bem... não me considero uma classe alta que tem alguns luxos econômicos que nós não temos. Eu adoro viajar, tentamos viajar, mas não o fazemos com tanta frequência. Mas tudo bem, não nos falta nada. Todas as necessidades básicas estão super satisfeitas, e mais ainda porque minhas filhas vão a uma escola pública [do Estado], mas também podem fazer atividades extra-escolares. Uma compete em patins, que é um dinheiro extra que nem todos podem dispor (...) temos dois [planos de saúde], o que nos desconta o governo [do salário] e outro que pagamos, que temos para as duas meninas e para mim (...) às vezes gostaríamos de nos dar alguns luxinhos, como viajar, trocar de carro? estamos bem, não nos queixamos de nada, temos cada um seu carro. Podemos nos movimentar bem (...) eu tenho meu carro e ele [o marido] tem um carro que ele gosta, que é como "o investimento". 
A classe média é o lugar social no qual se identifica a docente a partir de duas negações complementares. Não são de classe alta porque não tem todos os luxos daqueles, mas também não são de classe baixa já que as necessidades básicas estão plenamente satisfeitas. Os "luxos" operam como uma distinção em relação à classe baixa e como uma aproximação da alta: o carro que o marido gosta, dupla cobertura médica (uma pública e outra privada), atividades extracurriculares das filhas que são caras, são algumas das dimensões destacadas no relato. Podemos interpretar que esta construção de classe se dá em um contínuo biográfico que a habilitou quando jovem a tomar decisões de abrir ou fechar um maternal próprio ou, de ir estudar em Córdoba.

Na outra entrevistada observamos como também a autopercepção parece se ajustar com outras condições materiais de vida:

G: "a classe social de onde vinha [é] trabalhadora, pobre trabalhadora, assim te digo, pobre trabalhadora, agora é trabalhadora média, ninguém nos dá nada (...) [quando deixou o último trabalho, uma possibilidade era de que colocasse um negócio próprio] a indenização poderia levar a ter seu negócio [próprio, mas] eu precisava terminar minha casa (...) Não me pesou tanto e vivemos de um armazém (...) (Entrevistadora: E se tivesses que te inserir hoje? o que farias?)... Buscaria um trabalho com menos trocas de atividades, não correr daqui pra lá, então talvez secretária (...) me surgiu há três anos atrás uma proposta de trabalho importantíssima, muito boa, mas fizemos as contas, eu teria ido de olhos fechados porque era numa livraria, na parte de secretaria, de compras, de provedores, era mais ou menos a minha área mas daí, priorizei os filhos (...)".

Além de apontar as diferenças explícitas entre ambos os fragmentos, destacamos três aspectos. A entrevistada identifica uma leve mobilidade crescente em sua biografia. Na posição atual, pertencer a uma classe "trabalhadora-média" parece excluir o acesso a luxos e "presentes" - que no sentido metafórico significa que tudo o que possuem Ihes custou muito esforço. Por outro lado, os horizontes de possibilidades futuras se dão em condições passadas-presentes, por isso quando cobra a indenização não pode se arriscar a usar esse dinheiro em um negócio que pode ir mal. Comprar a casa é prioritário, portanto não há opção e por isso "vive do mercadinho". Em terceiro lugar, atualmente o horizonte do possível se encontra em um cargo de secretária ou pessoal 
administrativo em um comércio, no qual a diversidade de tarefas é limitada. Isto configura de maneira oposta em relação à sua experiência de trabalho anterior.

As percepções de classe dão conta de formas de vivenciar condições materiais e concretas de existência que se inscrevem em obstáculos e realizações configurados em suas trajetórias de classe. A seguir alguns fragmentos que dão conta de percepções que têm sobre si mesmas em relação ao trabalho:

L: "Eu sempre apostava mais, não queria ficar somente como professora. Eu sempre apostei, eu quero ser mais, sempre sonhava (...) eu adoro desafios, me cansa a monotonia e fazer algo por muito tempo (...) O que me move são as mudanças, fazer as coisas cada vez melhores e apostar para que em cada lugar, sempre se dê e se veja essa mudança, essa melhora. Apostar por? Com uns grãos de areia? Por uma graduação melhor, uma educação melhor (...) agora me sinto feliz porque é um cenário diferente, é totalmente outra realidade e tem múltiplos desafios. Agora me sinto muito respeitada, muito apoiada, mas quando comecei [recebia comentários de outros que se perguntavam] 'O que vai fazer esta, tão jovem?"'.

As configurações subjetivas se reinscrevem nos espaços de trabalho e encontram novos horizontes permanentemente. Realizações e crescimentos profissionais que acrescentam a disposição corporal/emocional a "apostar", que, como em um jogo, sempre existem duas possibilidades, ganhar ou perder. Neste caso as perdas podem ser compensadas, no qual os desafios, as mudanças e as apostas formam parte de tramas corporais que carregam uma trajetória de classe e uma sensibilidade particular. Passado, presente e futuro se metamorfoseiam nestas percepções, tal como acontece no caso da outra entrevistada:

G: "Eu estava tão acomodada, ganhava um salário, não tinha que levar uma casa adiante, eu estava feliz (...) está mal que eu o diga [diz isso como se lamentando], mas eu era boa no que fazia [quando trabalhava na loja], era muito responsável no meu trabalho (...) eu fazia mais do que podia fazer e o fazia bem, e fui ganhando bônus, jamais fui pedir aumento de salário, jamais (...) eu via que o patrão via tudo (...) Eu sabia que o único que podia chegar a ter em minha vida seria o mérito próprio do que eu conseguisse conquistar, conquistar [ressalta a palavra]". 
A comodidade de ser trabalhadora fica desfocada em um presente como dona de casa, mas por enquanto sem filhos, poderia desfrutar da felicidade do salário ganho -como em uma batalha. A autopercepção de eficiência como trabalhadora se combinava com práticas de "boa empregada" que não reclamava, que não se queixava e que estava atenta ao olhar do patrão que, como um panóptico, via tudo. As disposições à ação a colocam em um lugar diferente do da entrevistada anterior. Com se as trajetórias de classe resultaram em maior suportabilidade antes de arriscar perder esse trabalho; uma suportabilidade envolta de orgulho pelo que foi conquistado.

Neste segundo momento, dedicado à análise das entrevistas colocamos em relação as trajetórias de trabalho como indicadores de trajetórias de classe, a distribuição dos tempos em dupla jornada junto com as percepções de classe e autopercepções no trabalho. A conjunção destas dimensões nos permite compreender como as percepções se inscrevem em posições e condições de classe diferentes apesar de serem ambas muIheres, mães, esposas e trabalhadoras. Tais percepções também alertam sobre como vão se configurando sensibilidades no trabalho, e como a biografia como temporalidade corporal se inscreve em práticas, gostos e esquemas de classificação sobre aquilo que se pode escolher, buscar ou decidir.

\section{Considerações Finais}

Neste artigo nos propomos a indagar como se instanciam cotidianamente as metamorfoses do mundo do trabalho a partir das experiências de duas mulheres que trabaIham em setores tipicamente femininos na cidade: a docência e o comércio. Para isso distinguimos duas dimensões: trajetórias e tempos de trabalhos por um lado, e percepções por outro.

Seguindo os eixos conceituais de uma Sociologia dos corpos e das emoções nos aprofundamos no tempo como dimensão biográfica e social a partir da qual se configuram trajetórias de classe com suas respectivas posições e condições. Neste contexto problematizamos a feminização observando diferenças que, feitas corpos, configuram esquemas de percepção diferentes com respeito a si, de seus trabalhos, de seu pertencimento a uma classe social. 
Uma aproximação às entrevistas analisadas nos permite observar como as trajetórias de classe tornam diferentes as biografias de duas mulheres que desde a última década do século XX até a atualidade conheceram os dilemas da dupla jornada e compartilharam a provisão do lar com seus cônjuges.

"No" século XXI, encontramos mulheres que disputam espaços de hierarquia nas instituições feminizadas como é a docência mantendo não sem esforços e desgastes a dupla jornada, em lares que requerem dois provedores para pertencer a uma classe média com alguns "luxos". Por outro lado, da mão do crescente por conta própria, mulheres que preferem depois de ter trabalhado de maneira remunerada, priorizar o cuidado dos filhos e participar de maneira limitada no negócio do cônjuge (o mercadinho), uma vez que a certeza da "casa própria" foi alcançada (como se com o passar do tempo a norma aplicada na loja onde trabalhava $G$. de que as mulheres com filhos teriam que renunciar ${ }^{9}$ se tivessem posto em prática de maneira desapercebida). Por isso pode rechaçar ofertas de emprego diante estimativas de sentido prático - sensu Bourdieu - com respeito aos custos da terceirização do trabalho doméstico.

"No" século XXI, os corpos no capitalismo atual enfrentam consequências das metamorfoses do mundo do trabalho operadas desde fins do século anterior. As percepções das mulheres trabalhadoras que se inscrevem em suas trajetórias de classe portam as tensões de tais metamorfoses entre a estabilidade do emprego público e as opções do setor privado; entre as formas de expropriações de energias na polivalência de tarefas e a informalidade de ocupações; entre a dupla jornada para as mulheres e a manutenção do lar com um varão provedor.

Fica como tarefa questionar as descontinuidades que vêm com o novo século nas cidades intermediárias do Sul Global.

Tradução a cargo de Ana Pereira González e Kátia dos Santos Pereira.

\section{Referências}

BOURDIEU, P. Condición de clase y posición de clase. Revista Colombi-

\footnotetext{
${ }^{9} \mathrm{Em}$ outras entrevistas encontramos as mesmas referências no setor comercial, no sentido de que é maior o benefício quando a mulher não tem filhos e por onde se supõe que a dedicação ao trabalho é também maior.
} 
ana de Sociología, Bogotá, v.7, n.1, p.121-41. 2002. Disponível em: $<$ https://revistas.unal.edu.co/index.php/recs/article/view/11153/11819> Acesso em: 10 dic. 2017.

FEDERICI, S. El calibán y la bruja. Madrid: Traficantes de sueños, 2010.

MIES, M. Patriarchy and accumulation on a world scale. UK: Redwood books, 1994.

SCRIBANO, A. Estudios sobre Teoría Social Contemporánea: Bhaskar, Bourdieu, Giddens, Habermas y Melucci. Buenos Aires: CICCUS, 2008.

Sociología de los cuerpos/emociones. RELACES- Revista Latinoamericana sobre Cuerpos y Emociones, Buenos Aires, n10, p.93-113. 2012. Disponível em: <http://www.relaces.com.ar/index.php/relaces/article/viewArticle/224>. Acesso em: 24 nov. 2017.

VERGARA, G. Valoraciones frente a la desindustrialización. 2006. 199 p. Tesis (licenciatura en Sociología)- Universidad Nacional de Villa María - UNVM, Villa María, 2006.

Conflicto y emociones. Un retrato de la verguenza en Simmel, Elías y Giddens como excusa para interpretar prácticas en contextos de expulsión. In FIGARI C.; SCRIBANO, A. (comps.). Cuerpo(s), subjetividad(es) y conflicto(s). Hacia una sociología de los cuerpos y las emociones desde Latinoamérica. Buenos Aires: Ciccus-Clacso, 2009. p. 35-52.

- Experiencias de la doble jornada en mujeres recuperadoras de residuos de Córdoba en la actualidad. Un análisis de sus tramas corporales, percepciones y emociones. 2012. 289 p. Tesis (Doctorado en Ciencias Sociales)- Universidad de Buenos Aires-UBA, Ciudad Autónoma de Buenos Aires, 2012a.

Gasto festivo e temporalidade. As práticas desde os interstícios que descoIonizam o futuro. In SCRIBANO, A.; MAGALLANES, G.; BOITO, M.E. (comps). La fiesta y la vida. Estudios desde una sociología de las prácticas intersticiales. Buenos Aires: CICCUS, 2012b. p. 69-86.

Clases de miedos y miedos de clase. Un análisis de la emocionalidad en contexto de expulsión social en las mujeres recuperadoras de residuos de Córdoba (Argentina). In SALAZAR PÉREZ, R; HEINRICH, M. (comps.). Atrapados por el miedo. Buenos Aires: elaleph.com, 2013. p. 71-88.

Mujeres recuperadoras de residuos entre familias y trabajo: la percepción de proveer como amas de casa (Córdoba, 2006-2013). In (comp.). Recuperadores, residuos y mediaciones. Análisis desde los interiores de la cotidianeidad, la gestión y la estructuración social. Buenos Aires: ESE Editora, 2015. p. 229-60.

Cuerpos y sensibilidades en los trabajos: análisis de las metamorfosis en el siglo XXI. In: JORNADAS DE SOCIOLOGÍA UBA, 2017, Ciudad Autónoma de Buenos Aires. Inédito.

Transformaciones en el mundo del trabajo. In: Instituto de Ciencias Sociales de la UNVM (comp.), Villa María, Ediuvim, 2018a. No prelo.

. Cuerpos, sensibilidades y acción colectiva (Argentina, 2002). Estudos Feministas, Florianópolis, 2018b. No prelo. 
; FRAIRE, V. Cuerpos y sensibilidades en la ciudad. Análisis de prácticas de inmovilidad en/desde un barrio. In: CAMARENA LUHRS, M. (Coord.). Vida y vivencia en las ciudades de hoy. México: lisunam, 2017. p. 27-64.

; LISDERO, P. Acerca de las implicancias metodológicas de los conceptos: un esbozo desde el "mundo del trabajo" en el siglo XXI. In: GANDÍA, C. et al. (comps). Metodología de la investigación: estrategias de indagación I. Buenos Aires: ESE Editora, 2017. p. 127-151.

WEBER, M. La ética protestante y el espíritu del capitalismo. Buenos Aires: Prometeo, 2003. 